\title{
Challenging students to develop work-based skills: A PBL experience
}

\begin{abstract}
Alba Manresa, Jasmina Berbegal-Mirabent, Dolors Gil-Domenech
Department of Economy and Business Organisation, Universitat Internacional de Catalunya, Spain.
\end{abstract}

\begin{abstract}
In today's changing world the skills and habilities required for getting a job are rapidly changing. New trends such as globalization, data science, artificial intelligence and the never ending expansion of information and technology communications are changing the demands of the labor market. Accordingly, new skills are needed in order to succeed and get a job. As noted by the OECD, educators' challenge lies in helping students develop their unique capacity to create, innovate and add value, skills that distinguish humans from machines. With this aim in mind, this study reports the results of a challenge-based activity (based on project-based learning) targeted to undergraduate students in Business Administration. The results reveal a positive impact of the methodology on students' learning process, their satisfaction and a positive improvement on a series of skills, namely teamwork, writting and oral skills, digital skills, capacity to identify and solve problems, capacity to work autonomously, analytical capacity and capacity to think critically.
\end{abstract}

Keywords: Project-based learning; skills; B-Smart; operations management. 


\section{Introduction}

The 21st century is characterized for being full of innovations. All these innovations bring both opportunities and challenges which make businesses change their traditional way of operaring. Workplace, is not aside of these changes as job positions are becoming more flat, open, flexible and transparent.

In this context, there is a wide consensus about the importance of education, and more specifically on how students, during their years of schooling, can develop the skills that will be later required in their professional careers. Accordingly, we argue that as the market labor requirements are changing, also the way we teach students needs to be updated and ensure that when graduating, they are equipped with the right skills.

Universities play a crucial role in providing highly-educated people and in contributing towards fulfilling the needs of the industry. So relevant is the role of education that the Organisation for Economic Cooperation and Development (OECD) has launched a project (OECD Learning Compass 2030) in which it specifies which skills and competences should be taught and learned up to 2030. According to this project, skills are of three types (OECD, 2018): 1) cognitive and meta-cognitive skills, which include critical thinking, learning-tolearn, creative thinking, the capacity to find solutions to complex problems and selfregulation; 2) social and emotional skills, including empathy, self-efficacy, responsibility and collaboration; and 3) practical and physical skills, such as using new information and communication technology devices, or digital skills.

To cope with these demands, many universities have started changing their traditional way of teaching and align it better with the OECD's requirements. One strategy to address these demands in teaching is through active learning methods in which students become the center of the education processes being responsible of their learning process. Literature on active learning methods is rich and the advantages it provides are widely documented ( $₫$ svoll \& Jacobsen, 2012). Among the different strategies, Project-Based Leaning (PBL) stands as one of the most appropriate methods for the development of professional skills (Saorín et al., 2019).

PBL consists in presenting to students real problems that they must solve. As the project develops, the core concepts are progressively introduced and put into practice. In PBL the instructor acts as a mentor, guiding the learning process, and students become active parts, learning-to-learn as they develop an autonomous work, develop teamwork skills, and combine different knowledge areas that revolve around a common project (Disla García, 2013; Tippelt \& Lindemann, 2001). 
Several studies empirically validate that those students that used PBL are better at solving problems, have a higher capacity to pay attention and are more commited than those taught with traditional methods (Finkelstein et al., 2010; Thomas, 2000; Walker et al., 2009).

This article aims at describing and discussing a PBL activity implemented during the academic course 2019/20 at the Universitat Internacional de Catalunya (Barcelona, Spain) at the Operations Management course taught to third-year students enrolled in the Bachelor's Degree in Business Administration.

\section{Description of the activity}

\subsection{Project description}

The activity described is part of a teaching innovation project called B-SMART (which stands for Be Socially-engaged, Motivated, Agile, Resolute and Talented). This project is funded by the Fundació Puig through the Aula d'Innovació Docent of the Universitat Internacional de Catalunya and is lead by a group of lecturers from this university. The ultimate goal of this project is to narrow the gap between universities and businessess through the teaching mission. Specifically, the B-SMART project responds to those calls that ask for universities to enhance students' capacities and skills and for a closer cooperation between science and industry. To articulate the project, B-SMART challenges students to work in real-world projects posed by companies. By working side by side with the industry, students can apply their knowledge while develop some of the skills that the marketplace requires (e.g. entrepreneurship, creativity and innovation, critical thinking, teamworking).

\subsection{Teaching method}

Business challenges, which take the form of PBL, are solved using the design thinking, a methodology that is gaining momentum in the business world and is often refereed as anything from "a unified framework for innovation" to the "essential tool for simplifying and humanizing" (Kolko, 2015; Tuanli, 2016). It is a solution-focused, problem-solving and hands-on method that is extremely useful in tackling complex problems. While traditional business education has mainly relied in lectures and case studies, design thinking offers the unique opportunity to introduce real world challenges in the classroom. Following the model proposed by the Hasso Plattner Institute of Design at Stanford (commonly known as the d.school), design thinking is structured in five stages which, rather than being conceived as sequential steps, should be understood as different approaches that together, contribute to the entire design project: empathize (investigate users' needs), define (put all the information together and characterize the problem), ideate (think creatively challenging assumptions), prototype (start creating solutions) and test (try solutions out and get feedback from users). 


\subsection{The challenge}

The challenge described in this study was conducted at the Operations Management course, taught to third-year students of the Bachelor's Degree in Business Administration at the Universitat Internacional de Catalunya. For the academic year 2019/20, 30 students were enrolled, coming from different parts of the world, mostly from Italy and Spain, but also from Germany, Sweden, Peru and Ecuador.

This challenge involves different stakeholders: the company, the lecturers and the students. Starting with the first one, a company is invited to propose a real situation (or challenge) that it is facing to a group of students. With the support of the lecturer, the company prepares a case-study in which the challenge is described. A face-to-face conference with the students is organized in order to introduce them the company, explain the problem and provide students with all the information needed to solve the challenge. Additionally, the organization is also involved in the assessment of projects, taking part in the grading of the reports submitted by students. The top ten groups are given the opportunity to present their work in front of the CIO.

The second group of people involved are lecturers. In activites like the one described here, lecturers adopt a secondary role, acting as facilitators of the learning. This role also implies motivating the students and ensuring they complete the tasks. Besides clarifying concepts and ideas when needed in class, and grading the exercises afterwards, working with companies (using a challenge-based approach) requires extra time prior to the activity (e.g., contacting the company, preparing the case-study, etc.). Nevertheless, despite the extra work this activity implies, the lecturers participating in the teaching experience were happy with the results and showed interested in repeting the experience.

Finally, but not least, the last group of stakhodelrs are students. For the specific case of this activity, students were divided in groups of 5 and use the design thinking methodology to solve the challenge and suggest potential solutions. Each group delivered a report with their proposals. Also, students had to present their ideas in an oral presentation. As a way to give more credibility to the project, students also had to include a detailed list of the operations needed to implement their solutions and the costs that might entail. Both the instructor of the course and the industry partner were in charge of grading students as it is forementioned. .

\subsection{The company}

ADER Taxi Comercial (http://www.taxicomercial.com/en/) was the company in charge of posing the challenge. It is a freight company specialized in providing exclusive services to its customers with a driver. With almost 30 years of history, it offers specialized transportation services in the areas of distribution, freight and logistics. The challenge students had to solve consisted in providing solutions to improve the final consumer's 
experience in the delivery of orders. Students also had to evaluate how their solution will impact on the operator's resources and the potential influence on their business processes. Finally, they had to develop an action plan.

\section{Results}

In order to evaluate the usefulness of this activity, information on students' performance and satisfaction was collected.

Concerning skill acquisition, students were asked to anonymously respond a survey. Table 1 displays students' perceptions about skill improvement. Each item was evaluated in a sevenpoint Likert scale, were 1 indicates "strongly disagree" and 7 "strongly agree". As it can be inferred from the figures, students believed their skills to be enhanced thanks to the activity (average scores are over 5.5 in all instances). Particularly, the capacity to identify problems (6.13) and oral skills (6.07) are those skills that students felt that they developed the most. The item with the lower average score (5.52) referred to analytical capacity.

Table 1. Students' perceptions about the skills developed

\begin{tabular}{lcc}
\hline & Average score & Standard dev. \\
\hline My teamwork skills have improved & 5.70 & 1.09 \\
My oral skills have improved & 6.07 & 1.11 \\
My writing skills have improved & 5.80 & 1.16 \\
My capacity to identify problems has improved & 6.13 & 1.11 \\
My problem-solving skills have improved & 5.73 & 1.28 \\
My capacity to think critically has improved & 5.67 & 1.25 \\
My analytical capacity has improved & 5.52 & 1.31 \\
My capacity to work aunomously has improved & 5.60 & 1.22 \\
My digital skills (use of technology) have improved & 5.80 & 1.32 \\
\hline
\end{tabular}

Source: Own elaboration

As for the academic performance, grades were given based on the final report students submitted. The average score was 7.42. From the 6 groups that participated in the activity, one of them obtained the highest score (10). Three other groups were graded with a 8.5, one with a 6.5 and one group obtained a 5 . In the light of the results we can conclude that the activity was helpful for skill development and that students suggested relevant solutions with a real impact on the company. 
Concerning students' satisfaction, a survey was designed aiming at finding out their thoughts about the activity. The questions included in the survey, along with the average scores, are shown in Table 2. Each item was evaluated following a seven-point Likert scale ( $1=$ strongly disagree, 5 = strongly agree).

The results show that students were highly satisfied with the activity as the average scores for all items range between 5.23 and 6.75. Overall, students were satisfied with the activity (5.93) and they believed that it was very useful for their learning process (5.93). The item that students valued the most was the fact that the activity was real and that by solving it they were able to better understand how a company operates (6.23). They also valued high the chance to go depper into problems companies are facing nowadays (6.53). The methology used and how the activity was organized were also rated high (5.77 and 5.70, respectively). Students also expressed that this type of activity helped them to better understand the subject, and consequently, that they were more motivated and committed with the course. Contrarily, areas of improvement include a better definition of the activity. This perception of lack of a proper definition might be due to the fact that students are used to solve problems with only one solution and one (or few) possible(s) way(s) of reaching it. Real-world problems are typically ill-defined, and this type of activity trains them to open up their minds and think more creatively.

Table 2. Students' feedback (scale from 1, "strongly disagree”, to 7, “strongly agree”)

\begin{tabular}{lcc}
\hline & $\begin{array}{c}\text { Average } \\
\text { score }\end{array}$ & $\begin{array}{c}\text { Standard } \\
\text { dev. }\end{array}$ \\
& 5.23 & 1.25 \\
\hline The lecturer gave clear explanations & 5.60 & 1.19 \\
This activity made the subject more interesting & 5.67 & 1.15 \\
This activity motivated me to work & 5.77 & 1.17 \\
The use of design thinking is suitable to facilitate the learning process & 5.73 & 1.26 \\
This activity made the subject easier & 6.53 & 1.20 \\
This activity helped me to better understand companies' real problems & 6.23 & 1.01 \\
This activity helped me to better understand how a company works & 5.70 & 1.12 \\
The activity was well organized, prepared and structured & 5.93 & 1.01 \\
I think this activity is very useful & 5.93 & 1.11 \\
Overall satisfaction & & \\
\hline
\end{tabular}




\section{Conclusions and discussion}

In today's changing world, universities are expected to provide students with the right competences, skills and knowledge that will prepare them for the labor market. However, these requirements are constanly changing and consequently, it is necessary to continously adapt to the market. In this context, universities have aligned their courses with the labor market requirement. This study describes an activity conducted with students enrolled in a course on Operations Management, showing positive results on both students' performance and satisfaction. The ultimate purpose was to challenge students with a real project (with a company posing and evaluating it) so that by solving it, they develop some of the most relevant skills that the sector is asking for.

We argue that this type of activities is worth of being explored and implemented in class. First, the activity made the course more enjoyable for both the instructor and the students. Students felt more involved in the subject, but what is more important, the activity fostered deep learning, meaning that what students learnt was much better interiorized that by using traditional teaching methods. Additionally, the activity contributed to boost students' skills development, such as teamworking or problem-solving capacity, to name just a few. From the companies' perspective, the activity also had positive implications, as students are now better prepared, they are able to face, react and solve real problems and show higher commitment at their workplace.

Notwithstanding, based on the students' feedback, some ideas for improving this activity are envisioned. On the one hand, students reported some difficulties in understanding the main problem of the challenge. On the other hand, students found hard to complete the task within the given amount of time. More time to develop the project with the instructor and the industry partner - to make sure that all doubts are solved before the class ends- would had been helpful.

Despite this study provides useful insights for other educators, universities and companies, there are some limitations, which in turn represent new opportunities for future research. First, the number of students participating in this activity was low. Therefore the analyses of the students' performance, their feedback and skill acquisition were only discussed based on descriptive data. Additionally, with the data collected it was not possible to evaluate the degree of acquisition of the skills of interest, as there was no evidence of students' skills before the activity.

\section{References}

Åsvoll, H., \& Jacobsen, P. J. (2012). A case study: Action based entrepreneurship education. How experience problems can be overcome and collaboration problems mitigated. Journal of Entrepreneurship Education, 15, 75-97. 
Disla García, Y. I. (2013). Aprendizaje por proyecto: Incidencia de la tecnología de la información para desarrollar la competitividad de trabajo colaborativo. Ciencia y Sociedad, 38 (4), 691-718.

Finkelstein, N., Hanson, T., Huang, C. W., Hirschman, B., \& Huang, M. (2010). Effects of problem-based economics on high school economics instruction (NCEE 2010-4110). Washington, DC: U.S. Department of Education, Institute of Education Sciences, National Centre for Education Evaluation and Regional Assistance, Regional Educational Laboratory West.

Kolko, J. (2015). Design thinking comes of age. Harvard Business Review, September: 1-5.

Organisation for Economic Co-operation and Development (2018). The future of education and skills education 2030. https://www.oecd.org/education/2030/ E2030\%20Position\%20Paper\%20(05.04.2018).pdf

Saorín, J. L., de la Torre-Cantero, J., Melián Díaz, D., \& López-Chao, V. (2019). Cloudbased collaborative 3D modeling to train engineers for the Industry 4.0. Applied Sciences, 9(21), 4559.

Thomas, J. W. (2000). A review of research on project-based learning. San Rafael, CA: Autodesk Foundation.

Tippelt, R., \& Lindemann, H-J. (2001). El método de proyectos. El Salvador / Berlin: Ministerio de Educación y proyecto APREMAT, SLV/B7-310/IB/97/248, setiembre 2001. Retrieved from: http://www.halinco.de/html/doces/Met-proy APREMAT092001.pdf (accessed: January 15, 2020).

Tunali, K. (2016). Empathy, design thinking, and an obsession with customer-centric innovation. Forbes, January 17, 2016. Retrieved from: https://www.forbes.com/sites/sap/2016/01/17/empathy-design-thinking-and-anobsession- with-customer-centric-innovation/\#24096bd6e5e2 (accessed: January 15, 2020).

Walker, A., \& Leary A. (2009). Problem based learning meta-analysis: Differences across problem types, implementation types, disciplines and assessment levels. The Interdisciplinary Journal of Problem-Based Learning, 3(1), 12-43. 